\title{
EDITORIAL
}

\section{Darwin and microbiology}

This year marks the two-hundredth anniversary of Charles Darwin's birth and the one-hundredand-fiftieth anniversary of the publication of On the Origin of Species. Darwin's ideas have influenced biology ever since, but his impact on microbiology is less well appreciated.

Charles Darwin and his theory of the origin of species bring to mind, first and foremost, finches. The slight variations in the beak structures of finches on the Galapagos Islands are the best-known example of the influences on Darwin's thinking on how species evolved. His ideas on 'survival of the fittest' and selection during evolution are the guiding principles in nearly all aspects of biology, and his ideas influence microbiology today.

Microbiology was a young science when Darwin published On the Origin of Species in 1859. No techniques existed for the isolation of bacteria, and the tremendous diversity of the microbial world was still largely unknown. The germ theory - the idea that diseases are caused by microorganisms - would not be developed until many years later. However, although Darwin did not publish on microbiology and is not known to have worked with bacterial cultures, he did have an interest in microbiology, which was spurred on, in part, by his health problems. For most of his life Darwin suffered from stomach problems, which have been attributed to various causes, including Chagas' disease, lactose intolerance and hypochondria. He consulted Sir John Goodsir, a leading medical expert in his day who had shown that 'animalcules', singlecelled microorganisms, could be detected in the vomit of patients with gastric ulcers. Darwin most likely examined his own vomit for the presence of Sarcina, the organism discovered by Goodsir. This microbiological adventure left him disappointed, as he saw no Sarcina; however, in his correspondence he reports seeing 'eels of Torula' (yeast) and spores of Penicillium. Darwin was also interested in Phytophthora, the widely dispersed plant pathogen, and the attempts to grow Phytophthora-resistant plants, and was fascinated by the many algae he encountered on his voyage ${ }^{1}$.

Darwin also had a keen interest in the origin of life $\mathrm{e}^{1,2}$, a topic that is still hotly debated by microbiologists today. During his lifetime, he witnessed a vigorous debate on the origin of life, which pitted those who believed in spontaneous generation against those who supported the idea that life is always pre-existing. Darwin's theory does not explain the origin of life and, in fact, Pasteur's demonstration that life cannot arise spontaneously, which swayed the debate permanently against spontaneous generation, can be seen to undermine Darwin's theory. Darwin, however, realized that the origin of life and the selection of species are separate events and postulated that life could have arisen in a 'warm pond', after which it would have been bound by the laws of natural selection. He stated in one of his letters, "As for myself I cannot believe in spontaneous generation...." Darwin was also a participant in a study by John Tyndall, from whom he received a tube of sterile broth that he exposed to the air to show that only then did it become cloudy and filled with bacteria, demonstrating that life was acquired from the air and did not arise spontaneously.

Other aspects of his book continue to have an important role in microbiology. The only illustration in On the Origin of Species is a tree of life, which he used to explain the relationship between species and the success and loss of related species. Although today the concept of a tree of life, particularly to portray the phylogenetic connection between bacteria, is hotly debated, for many years it has served to explain how bacteria are related.

But it is in medicine in which we see the most striking example of Darwin's principles at work: drugresistant pathogens. The overuse of antibiotics creates niches where only resistant pathogens can survive. In the absence of competition, these pathogens quickly thrive and spread among the population. However, using Darwinian principles, new treatment regimens, such as cycling of antibiotics, are being devised to decrease the chances of resistance arising.

So although Darwin is not considered one of the greats of microbiology, his work is inextricably woven into the fabric of our science, making this year's celebrations of his life and work as relevant to those who work on microorganisms as it is to those who work on macroorganisms.

\footnotetext{
Wainwright, M. Historical perspectives: Charles Darwin and microbes. Microbiologist 10, 32- 35 (2009)

2. Pallen, M. Darwin: from the origin of species to the origin of infection. Microbiology Today 36, 76-78 (2009).
} 